\title{
Channel Conflict and Coordination in the E-Commerce Age
}

\author{
Andy A. Tsay • Narendra Agrawal \\ Leavey School of Business, Santa Clara University, Santa Clara, California 95053-0382, USA \\ atsay@stanfordalumni.org・nagrawal@scu.edu
}

\begin{abstract}
$\mathrm{A}$ number of factors, including developments in Internet-based commerce and third-party logistics, have led many companies to consider engaging in direct sales. Such a company may at once be both a supplier to and a direct competitor of any existing reseller partners (e.g., land-based retailers), which can result in "channel conflict." This can have momentous implications for distribution strategy.

To generate managerial insights into this important issue, we develop a model that captures key attributes of such a setting, including various sources of inefficiency. We examine these in detail and identify a number of counterintuitive structural properties. For instance, the addition of a direct channel alongside a reseller channel is not necessarily detrimental to the reseller, given the associated adjustment in the manufacturer's pricing. In fact, both parties can benefit.

Finally, we examine ways to adjust the manufacturer-reseller relationship that have been observed in industry. These include changes in wholesale pricing, paying the reseller a commission for diverting customers toward the direct channel, or conceding the demand fulfillment function entirely to the reseller. The latter two schemes could be mutually beneficial in that they achieve a division of labor according to each channel's competitive advantage.
\end{abstract}

Key words: retail sales; direct sales; catalog sales; resellers; intermediaries; electronic commerce; Internet commerce; channels of distribution; dual distribution; channel conflict; supply chain management; coordination; mathematical modeling; game theory

Submissions and Acceptance: Received March 2002; revision received November 2002; accepted April 2003.

\section{Introduction}

For any company with a product to sell, how to make that product available to the intended customers can be as crucial a strategic issue as developing the product itself. While distribution strategy is a very traditional concern, for many companies it has recently come under intense scrutiny due to a number of major developments. First, the expanding role of the Internet in consumer and business procurement activity has created unprecedented opportunities for easy and vast access to customers. And second, the economics of materials delivery has been revolutionized by the efficient and pervasive logistical networks deployed by third-party shipping powerhouses, such as Federal Express and United Parcel Services. As a result, many manufacturers are reconsidering whether they should rely on intermediaries (we will refer to these as "resellers," so that our logic applies not only to retailers, but also various forms of distributors, wholesalers, etc.), sell directly to end customers, or even pursue both approaches in parallel. ${ }^{1}$ The intent of this paper is to provide rigorous insight into this issue, which will necessitate proper acknowledgment of the objectives and likely reactions of the resellers.

Firms in a variety of industries have recently established avenues for selling direct (e.g., Nike, Estee Lauder, Mattel, Eastman Kodak, IBM, the former Compaq, Dell Computer, Cisco Systems, etc.), and still others are seriously evaluating such strategies (cf. Stern, El-Ansary, and Coughlan 1996; Collinger 1998; Hamer and Sample 1998; Schonfeld 1998; Goldman

\footnotetext{
${ }^{1}$ In general, this decision entails a determination of the number of levels in the distribution network, the number of outlets within each level, and other variables, such as pricing, inventory levels, service levels, etc. The traditional marketing literature refers to these as distribution strategy, distribution intensity, and distribution management, respectively (Corstjens and Doyle 1979). In this paper, we focus on the strategy and management activities.
} 
1999; Janah 1999; Kravetz 1999; Bannon 2000). Specific motivations for this include the following: (1) resellers carry only small assortments of a manufacturer's products, (2) direct control of distribution and pricing can lead to higher profit margins, (3) resellers can use their power to extract various concessions from the manufacturers, (4) manufacturers can provide a broader product selection in a better ambiance with higher service in direct outlets, (5) more flexibility in experimenting with product attributes, (6) closer contact with customers, and (7) protection from crises faced by resellers (Stern, El-Ansary, and Coughlan 1996). Eliminating intermediaries ("disintermediation") can also improve supply chain efficiency, by allowing upstream parties better visibility into market demand (cf. Lee, Padmanabhan, and Whang 1997). While these arguments have long supported the use of catalog sales and company-owned stores, they are just as relevant when the markets are created via the Internet. Indeed, the explosion in possibility of electronic commerce is what has drawn many manufacturers into the realm of direct sales. ${ }^{2}$

Elimination of intermediaries is not without disadvantage, though. The role of intermediaries is to efficiently create and satisfy demand, through activities that include building brand and product awareness through advertising and customer education, providing market coverage, gathering market information, providing breadth of assortment, processing orders, customer support, etc. We refer to these collectively as "sales effort." If a manufacturer cannot otherwise attend to these functions efficiently, elimination of intermediaries may cause an erosion of profits, market share, or both (cf. Ghosh 1998). As noted by Stern, El-Ansary, and Coughlan (1996, p. 115), "It is an old axiom of marketing that it is possible to eliminate wholesalers (or any middlemen, for that matter) but impossible to eliminate their functions."

Retaining both channels (direct and reseller-intermediated) is a compromise alternative which may enable greater market penetration than using either one alone. However, this establishes the manufacturer as a direct competitor to its reseller partner, potentially leading to tension referred to as "channel conflict." ${ }^{3}$ For example, Nike's opening of its Niketown

\footnotetext{
${ }^{2}$ We should be careful to note that the use of Internet/catalog/phone sales does not necessarily constitute a direct channel, as in many cases, this still represents reseller-intermediation. One obvious example is Amazon.com, which our framework would still treat as a reseller.

${ }^{3}$ Stern, El-Ansary, and Coughlan (1996) use this term to broadly describe any sort of conflict of interest across channels. Also, adding a distribution channel can create channel conflict, whether the new channel is owned by the manufacturer or involves other intermediaries. Our use of the term focuses specifically on resellers' concerns about the installation of a manufacturer-direct channel since this represents a growing trend in industry.
}

store in downtown Chicago was considered a serious threat by retailers carrying Nike products (Collinger 1998). Estee Lauder's plans to sell its flagship Clinique brand directly over the Internet put it squarely in competition with the department stores whose cosmetics counters feature its products so prominently (Machlis 1998b). Similar conflicts have been reported by Avon Products Inc. (Machlis 1998c), Bass Ale (Bucklin, Thomas-Graham, and Webster 1997), IBM (Nasireti 1998), Mattel (Bannon 2000), and others. Some trade groups, such as the National Shoe Association and the National Sporting Goods Association, have gone to the point of urging members to reduce or eliminate purchases from manufacturers establishing direct sales outlets (Stern, El-Ansary, and Coughlan 1996). A well-publicized incident involved letters sent in May of 1999 by Home Depot to more than 1,000 of its suppliers, stating "Dear Vendor, It is important for you to be aware of Home Depot's current position on its' [sic] vendors competing with the company via e-commerce direct to consumer distribution. We think it is short-sighted for vendors to ignore the added value that our retail stores contribute to the sales of their products.... We recognize that a vendor has the right to sell through whatever distribution channels it desires. However, we too have the right to be selective in regard to the vendors we select and we trust that you can understand that a company may be hesitant to do business with its competitors" (Brooker 1999). In general, channel conflict can undermine attempts to develop cooperative relations in the intermediated channel, which may lower the profits of all parties.

The desire to use both channel types may compel a manufacturer to redefine its relationship with the intermediary, with careful attention to the division of labor and any associated financial terms. For instance, in 1998, the former Compaq unveiled an aggressive effort to sell personal computers directly to end customers (using Internet and telephone sales), bypassing the dealers who helped make it one of the world's largest sellers of PCs. To appease its dealers and distributors, Compaq's plan included maintaining separate brands for small business and corporate markets and paying dealers an estimated $6 \%$ commission for referring small business customers (McWilliams 1998). On the other hand, while IBM may take orders for PCs over the Web, it redirects the sales to its distributors (Girishankar 1998), and allows some of them to add further value by performing a variety of assembly steps (Nasireti 1998). Hewlett-Packard's "Commerce Center" is not an on-line store per se-it simply gives business customers an easy, point-and-click way to order from an HP reseller (Janah 1999; Garner 1999). Customers have access to Sun Microsystems' online Sun Store only if they already have a sales representative, who then receives a commission on these sales 
(Garner 1999; Goldman 1999). Orders placed at the Web site of Ethan Allen Interiors Inc. are filled at the nearest retail store $(60 \%$ of the 300 stores nationwide bearing this furniture company's name are owned by independent licensees), which receives $70 \%$ of the profit for its trouble (Goldman 1999). When consumers book flights on the Travelocity Web site, all actual ticketing is still left to a partner travel agent in order to keep the channel involved (Machlis 1998a). Estee Lauder gives visitors to www.clinique.com a choice to place orders directly or with one of several national retailers linked to the site, and tries to drive additional traffic to retail stores by recommending complementary products (Machlis 1998b). On the upscale Bobbi Brown cosmetics line, online orders are fulfilled by Neiman Marcus (Garner 1999). And although one of the chief attractions of Internet selling is supposed to be lower prices, firms including Mattel (Bannon 2000) and Intuit (Machlis 1998a) maintain Web prices at a level that do not undercut retail sellers of their products. Likewise, in addition to promising not to discount online, Clinique has vowed not to offer the special free gifts that have proven to be so instrumental in department store promotions (Garner 1999). On the other extreme, Bass Ale altogether abandoned its foray into direct sales due to pressure from its key retailers (Bucklin, Thomas-Graham, and Webster 1997). And at least one of Home Depot's suppliers, tool manufacturer Stanley Works, has scrapped its e-commerce plans in response to the May 1999 warning letter (Brooker 1999).

It should be evident that, to effectively assess the costs and benefits of multi-channel distribution, manufacturers and resellers alike must understand the nature and extent of the potential channel conflict. As Frazier (1999) notes, "While multiple channels potentially increase the firm's penetration level and raise entry barriers, intrabrand competition and intrachannel conflict may become major problems, leading to lowered levels of support in the firm's direct and indirect channels. Such possibilities remain largely unexplored."

Our objective is to generate managerial insights into the dynamics of channel conflict by modeling a stylized supply chain with independent decision-making at both the manufacturer and reseller levels. We will evaluate the individual behaviors under three different distribution strategies: (1) only reseller sales, (2) only direct sales, and (3) both channel types together. These will be compared with benchmark systems which are centrally controlled. Finally, we will investigate mechanisms for improving individual and system performance, and compare with schemes that have been observed in industry.

The remainder of our paper is organized as follows. Section 2 discusses relevant literature. Section 3 details our modeling assumptions, while Section 4 presents analysis of the three cases. Alternative incentive schemes are discussed in Section 5. A summary of key results and concluding remarks are presented in Section 6. All relevant proofs are relegated to the Appendix for clarity of exposition.

\section{Literature Review}

Analysis of distribution systems is the focus of much of the multi-echelon inventory literature. Federgruen (1993), Muckstadt and Roundy (1993), and Axsater (1993) review some of this literature. Such papers provide considerable attention to modeling the flows of materials and information within distribution systems and use the resulting characterizations to derive effective material control policies. However, most papers in this area take the structure of the distribution system as given, and central control is also a common assumption. Consequently, the type of channel conflict that we consider is not addressed.

A second class of literature explicitly considers the structure of the distribution system as a decision variable. Building upon initial work by Artle and Berglund (1959) and Balderston (1958), Baligh and Richartz (1964) consider the problem of designing the optimal distribution system to transfer materials from multiple manufacturers to multiple retailers for a single product. They determine the number of levels in this system as well as the number of firms within each level to minimize the communication and contact costs in the network. However, typical supply chain decisions, such as inventory, pricing, and service, are ignored in this paper. Naert (1971) extends this work by considering consumer and intermediary advertising, which have properties similar to our "sales effort." Corstjens and Doyle (1979) consider multiple aspects of distribution system design by modeling sales as a function of the number of intermediaries, the number of levels, and price, although no concept of effort appears in the formulation. Cross price elasticities across the firm's channels are included, as are constraints on the number of channels and total production capacity. Because of the complexity of the resulting model, special techniques described as "geometric programming" are required to compute the profit-maximizing distribution strategy. Along similar lines, Rangan (1987) models market share as a function of channel effort (e.g., inventory, service, customer calls), non-channel effort (e.g., pricing strategy), and the channel structure. He develops a mathematical-programming-based decision support system for optimizing the distribution system's design. Jaikumar and Rangan (1990) and Rangan and Jaikumar (1991) study how price rebates offered to different intermediary levels affect the channel choice decision, and use 
this model to determine the optimal pricing and distribution strategy. Cohen, Agrawal, Agrawal, and Raman (1995) perform an industry-level analysis of distribution networks by focusing on the specific functions performed by intermediaries (redistributors), for which the intermediaries charge their customers (distributors) a premium relative to prices for direct purchases from the manufacturers. Cohen, Kleindorfer, and Lee (1990) and Cohen, Zheng, and Wang (1999) analyze service parts logistics systems, where parts can reach customers through service depots as well as directly from the manufacturer's warehouses. While papers in this second category examine the structural design issues in great detail, they all assume central control of the distribution system. Consequently, they too fail to model channel conflict, and are therefore silent on the issue of managing the relationships among the involved parties.

A third category of literature explicitly models the individual incentives of different parties in a channel and pursues mechanisms which can improve the performance of the system without compromising local decision authority (see Tsay, Nahmias, and Agrawal 1999 and Frazier 1999 for recent reviews). These papers tend to sacrifice richness of structural detail to facilitate the formation of managerial insights about inter-firm relations. Specifically, such models are typically stylized representations of channels with two levels and a small number of competing players (often one or two) at each level. In this category, there is a long history of research in the economics literature. Tirole (1988) and Katz (1989) provide excellent reviews of the early work in this area. For example, Dixit (1983) and Mathewson and Winter (1984) consider the use of resale price maintenance and lumpsum payments, while Bowman (1955), White (1981), and Bolton and Bonnano (1987) consider price discrimination. Telser (1960), Yamey (1954), Mathewson and Winter (1984), and Perry and Porter (1990) consider the case where externalities stemming from promotional or service activities may exist. They study how resale price restrictions may mitigate any incentives that dealers may have to "free-ride" upon a competitor's promotional activities. Silcock (1938) and Marvel and McCafferty (1984) consider the effect of product or dealer reputation. More recently, in a seminal work, Jeuland and Shugan (1983) characterize the nature of inefficiency in a bilateral monopoly channel and demonstrate that quantity discounts can achieve coordination in such a system. Moorthy (1987) shows that Jeuland and Shugan's channel can be coordinated by a two-part tariff in which the product is sold to the retailer at the manufacturer's marginal cost and a franchise fee serves to allocate profits between the manufacturer and the retailer (see also Oi 1971 and
Schmalensee 1981). Desiraju and Moorthy (1997) extend this analysis by considering asymmetry in the manufacturer's and retailer's information about a demand curve that is sensitive to both price and service, and show that performance requirements on service are necessary to coordinate such a system. Other papers have focused on competition between multiple manufacturers and/or retailers. McGuire and Staelin (1983) consider two single-item manufacturers each selling through exclusive retailers, with partial substitutability between the products (i.e., the manufacturers compete in the retail markets). McGuire and Staelin (1986) explore additional channel management strategies and characterize coordination mechanisms. Ingene and Parry $(1995,1998)$ discuss coordination of a distribution system in which two asymmetric retailers engage in price competition in the resale of the product of a common manufacturer. Choi (1996) and Trivedi (1998) model competition at the retail as well as manufacturer levels. Tsay and Agrawal (2000) extend Ingene and Parry $(1995,1998)$ by generalizing the retail competition to both price and non-price dimensions. For an earlier review of the application of such game-theoretic approaches to model competition, see Moorthy (1993). Katz (1989), O'Brien and Shaffer (1992), McAfee and Schwarz (1994), and Chen, Federgruen, and Zheng (2001) are among those who consider coordination issues with an arbitrary number of retailers.

Within this third class of literature, a number of papers about various aspects of hybrid distribution systems with independent intermediaries have arisen very recently. These include Rhee and Park (2000), Hendershott and Zhang (2001), Rhee (2001), Chiang, Chhajed, and Hess (2002), and Peleg and Lee (2002), in which customers have an option for direct delivery from the manufacturer, and Boyaci (2001), Bell, Wang, and Padmanabhan (2002), and Ahn, Duenyas, and Zhang (2002), in which customers can shop in physical stores owned by the manufacturer. One distinction of our model is that it is sufficiently general to consider the logistics and marketing cost signatures of either type of manufacturer-controlled channel, which can differ dramatically. Another is our consideration of channel coordination and a variety of schemes that industry has attempted as a way to mitigate concerns about channel conflict. See Tsay and Agrawal (2002) for extended discussion of the differences among these pieces of research.

\section{Model Structure}

We consider a single product which can be offered to the end market through a variety of channel strategies. In the "direct sales" approach (DS), the manufacturer not only provides the product, but also elects to per- 
form those activities necessary to stimulate and fulfill market demand. Alternatively, the manufacturer may turn to an independent intermediary (which we call a reseller) capable of performing such activities more effectively, but which must be somehow compensated for this. This is the "reseller-only" approach (R). A third possibility combines the preceding two options, which we label as the "both channels" (B) approach. The following model represents these alternatives in a way that will offer insights about the decision of how to deliver a product to market, and how different incentive schemes might affect the profits accruing to the various parties in the supply chain.

\subsection{Demand Model}

We denote the sales volume in the direct and reseller channels as $D_{d}$ and $D_{r}$, respectively. These depend on the channels' sales effort as described in Table 1, where $s_{r}$ and $s_{d}$ represent effort by the reseller in the reseller channel and the manufacturer in the direct channel, respectively.

Regardless of the choice of channel strategy, the demand in each channel is an increasing function of the sales effort within that channel. When both channels are open, sales effort in either channel exhibits a positive externality for the other, ${ }^{4}$ with magnitudes represented by $b_{r}, b_{d}>0$. This formalizes a belief held in many industries (Bucklin, Thomas-Graham, and Webster 1997; McIntyre 1997; Schmid 1999). However, even if a multi-channel approach increases the total demand, the individual firms will ultimately be interested in how this demand will be allocated between the channels. We model this effect with the parameter $\chi \in[0,1]$, which describes the fraction of the effortdriven component of total demand that is captured by the direct channel. ${ }^{5}$ This reflects in a very aggregate way the specific attributes of customers' behavior that

\footnotetext{
${ }^{4}$ It should be understood that this representation limits consideration to forms of sales effort whose impact on a customer is not contingent on the purchase being transacted in a particular channel. This best applies to efforts to build brand or product awareness. For instance, by providing extensive product information through advertising, printed materials, Web sites, or live technical support, a manufacturer can drive sales through resellers as well as through its own direct channels. Likewise, a retailer whose stores house knowledgeable salespeople and product samples, and whose advertising prominently promotes a manufacturer's product, may win customers for both channels.

${ }^{5}$ For simplicity, we assume $\chi$ to be independent of the sales effort. This is plausible if the effort component of the interaction delivers the same value to an end customer, regardless of where the actual purchase is made. This assumption could be relaxed by using $\chi$ $=\chi\left(s_{r}, s_{d}\right)$ with $\partial \chi / \partial s_{d} \geq 0$ and $\partial \chi / \partial s_{r} \leq 0$, suggesting that increasing sales effort in a channel should not only increase overall demand, but will also render that channel differentially more attractive. This, of course, would substantially complicate the analysis.
}

Table 1

Demand Functions

\begin{tabular}{lccc}
\hline & \multicolumn{3}{c}{ Distribution strategy } \\
\cline { 2 - 4 } Demand & $\begin{array}{c}\text { Direct sales } \\
\text { (DS) }\end{array}$ & $\begin{array}{c}\text { Reseller-only } \\
\text { (R) }\end{array}$ & $\begin{array}{c}\text { Both channels } \\
\text { (B) }\end{array}$ \\
\hline Direct channel $\left(D_{d}\right)$ & $s_{d}$ & $s_{r}$ & $\begin{array}{c}\chi \cdot\left(b_{r} s_{r}+b_{d} s_{d}\right) \\
(1-\chi)\left(b_{r} s_{r}+b_{d} s_{d}\right)\end{array}$ \\
Reseller channel $\left(D_{r}\right)$ & & & \\
\hline
\end{tabular}

determine their channel preference. ${ }^{6}$ One might anticipate that the larger the $\chi$, the greater will be the objection of the reseller to the presence of the direct channel. We will investigate this notion. Note that, while the addition of a channel has the potential to increase the size of the total market, this is not guaranteed when individual reactions are taken into account. Indeed, as we will show, in equilibrium the reseller may choose to promote the item less if the direct channel is opened. Managing this dynamic is crucial to distribution strategy, as noted in Section 1.

Since experience has indicated that customers' channel patronage choices are significantly determined by non-price factors, we assume the retail price to be fixed, and independent of the channel of delivery. ${ }^{7}$ This allows us to focus on the economics of the relationships between channel entities. Indeed, in many situations, manufacturers who sell through both direct and reseller channels deliberately avoid undercutting the reseller to avoid channel conflict $^{8}$ (cf. Stern, El-

\footnotetext{
${ }^{6}$ Even when controlling for any price motive, there will be reasons why a customer might prefer purchasing from one channel over another. Buying from a local reseller can offer the ability to experience the product before purchase (possibly under the guidance of a knowledgeable salesperson), the gratification of obtaining the product right away, and convenience in making a return or exchange. On the other hand, buying direct from the manufacturer oftentimes enables product customization, albeit with a delay in demand fulfillment. This has been made viable relatively recently by flexible manufacturing techniques and the expanding role of the Internet as a conduit by which customers can both passively and actively declare their individual preferences, as evidenced by the direct sales initiatives of companies such as Mattel, Levi-Strauss, BMW, and Dell Computer (Schonfeld 1998). Also, the crowds occasionally associated with the retail shopping experience, while enjoyable to some, are anathema to many. Indeed, many attribute the ongoing growth in "e-tail" (electronic retail) to this factor.

${ }^{7}$ Analysis of a generalized model with price as a control variable has replicated our major findings about manufacturer and reseller preferences for the various distribution strategies. Details are available from the authors.

${ }^{8}$ Even in the recent "land-grab" phase of online retail, most of the dramatic undercutting of bricks-and-mortar retail prices was done by overzealous e-tailers rather than the manufacturers themselves. And subsequent experience has shown that this was generally an aberration, sustainable only as long as the financial markets were willing to subsidize money-losing businesses. Those e-tailers that have not already gone out of business have generally raised prices and eliminated perks such as unrestricted free shipping. Instead, the survivors are banking their future on their ability to win customers by non-price means such as providing a superior shopping experience.
} 
Ansary, and Coughlan 1996; Machlis 1998b; Goldman 1999; Tedeschi 1999; Bannon 2000). On the other hand, many products sold this way are very price-competitive (e.g., books, music CD's, consumer electronics), so that neither resellers nor direct sellers can deviate far from the prevailing market price (adjusted for any shipping costs). Either way, the differentiation between channels will be achieved along non-price dimensions that can include those affected by our sales effort construct. This assumption also ignores any intangible benefits that may accrue to the seller even when the explicit revenue on a sale is identical in both channels. For instance, some manufacturers believe that selling direct allows the cultivation of a more sustainable relationship with the end customer, which may have long-term benefits (cf. Ghosh 1998).

\subsection{Cost Structure}

The reseller's cost of providing sales effort level $s$ is represented as $\eta_{r} s^{2} / 2$, whereas the manufacturer would have to spend $\eta_{d} s^{2} / 2$ to achieve the same effect in the direct channel. We assume $\eta_{r}<\eta_{d}$ to indicate that the reseller has some comparative advantage in stimulating demand. This is usually attributed to the economies of scale and scope in "marketing" that contribute to the reseller's raison d'être. The quadratic form serves to bound system profits and suggests diminishing returns on sales effort expenditures. Its appropriateness is discussed further by Desiraju and Moorthy (1997), Tsay and Agrawal (2000), and references within. Non-negativity of sales effort levels in the multi-channel equilibrium requires the following assumption:

$$
\eta_{d} / \eta_{r}>\left(b_{d} / b_{r}\right)^{2}
$$

Economically, this renders the creation of demand through the direct channel sufficiently costly that the reseller channel will not be completely dominated by the direct channel.

Other financial flows throughout the system are described by the following parameters:

$c_{i}=$ supply chain costs incurred by the manufacturer per unit sold through channel $i(i \in\{r, d\})$

$w=$ unit wholesale price paid by the reseller to the manufacturer

$p=$ unit selling price for the product $\left(p \geq c_{r}, c_{d}\right)$.

The two distinct supply chain cost parameters, $c_{d}$ and $c_{r}$, are used to distinguish between the production/logistics methods needed to deliver direct to end customers vs. to an intermediary. This also allows our deterministic framework to approximate some channel issues which are made relevant by uncertainty in market demand. For instance, as noted earlier, one argument in favor of direct sales is that, when demand forecasting is necessary, the insertion of an intermediary tends to distort the upstream flow of information.
This is one explanation for the "bullwhip effect," which is blamed for high inventory and/or low service levels in many supply chains (cf. Lee, Padmanabhan, and Whang 1997). Moreover, multi-echelon channels may also maintain safety stock at multiple levels. We use the relative values of $c_{r}$ and $c_{d}$ to proxy the overall efficiency of each supply channel, including inventory-related costs. We assume that both channels attempt to provide similar service levels to the end customer by holding the requisite safety stock. The cost of this inventory is then incorporated into the unit cost, an approach typical of standard cost accounting practices. This enables comparison on common terms. So, if $c_{d}>c_{r}$, the logistical inefficiency of direct sales (i.e., shipping in relatively low volumes, usually through third parties such as UPS or Federal Express) and the cost of providing any product customization outweigh any inventory advantages from cutting out the intermediary; $c_{d}<c_{r}$ means the opposite, that direct sales can deliver product for a lower overall cost per unit (for instance, in the PC industry, selling direct also facilitates an "assemble-to-order" strategy that typically entails less inventory risk than the "make-tostock" approach of retail distribution).

Hence, the differentiation in the inherent capabilities of the channels is made along two separate dimensions, which correspond roughly to the functional areas of "operations" and "marketing": the magnitudes of $c_{d}$ and $c_{r}$ capture the differences in production and logistics efficiencies, and $\eta_{d}$ and $\eta_{r}$ reflect the relative efficacy of the channels in stimulating demand. We do not consider any fixed or overhead costs associated with maintaining a channel. The presence of these would tend to discourage the simultaneous use of multiple channels.

Figure 1 summarizes the problem structure graphically.

\section{Analysis}

Given the stated structure, we can formulate each entity's decision problem under the various system configurations and solve for the resulting behavior and performance outcomes.

The manufacturer's profit is

$$
\pi_{M}=\left(w-c_{r}\right) D_{r}+\left(p-c_{d}\right) D_{d}-\eta_{d} s_{d}^{2} / 2,
$$

and the reseller's profit is

$$
\pi_{R}=(p-w) D_{r}-\eta_{r} s_{r}^{2} / 2 .
$$

The demand functions, $D_{r}$ and $D_{d}$, vary with the channel strategies as detailed in Table 1.

In DS, the manufacturer sets the sales effort $s_{d}$ to maximize $\pi_{M}$. In $\mathrm{R}$, the manufacturer acts as Stackelberg leader in setting $w$, which the reseller treats as given in choosing $s_{r}$ to maximize $\pi_{R}$. The decision 
Figure 1 Decisions and Demand Responses in the Distribution System

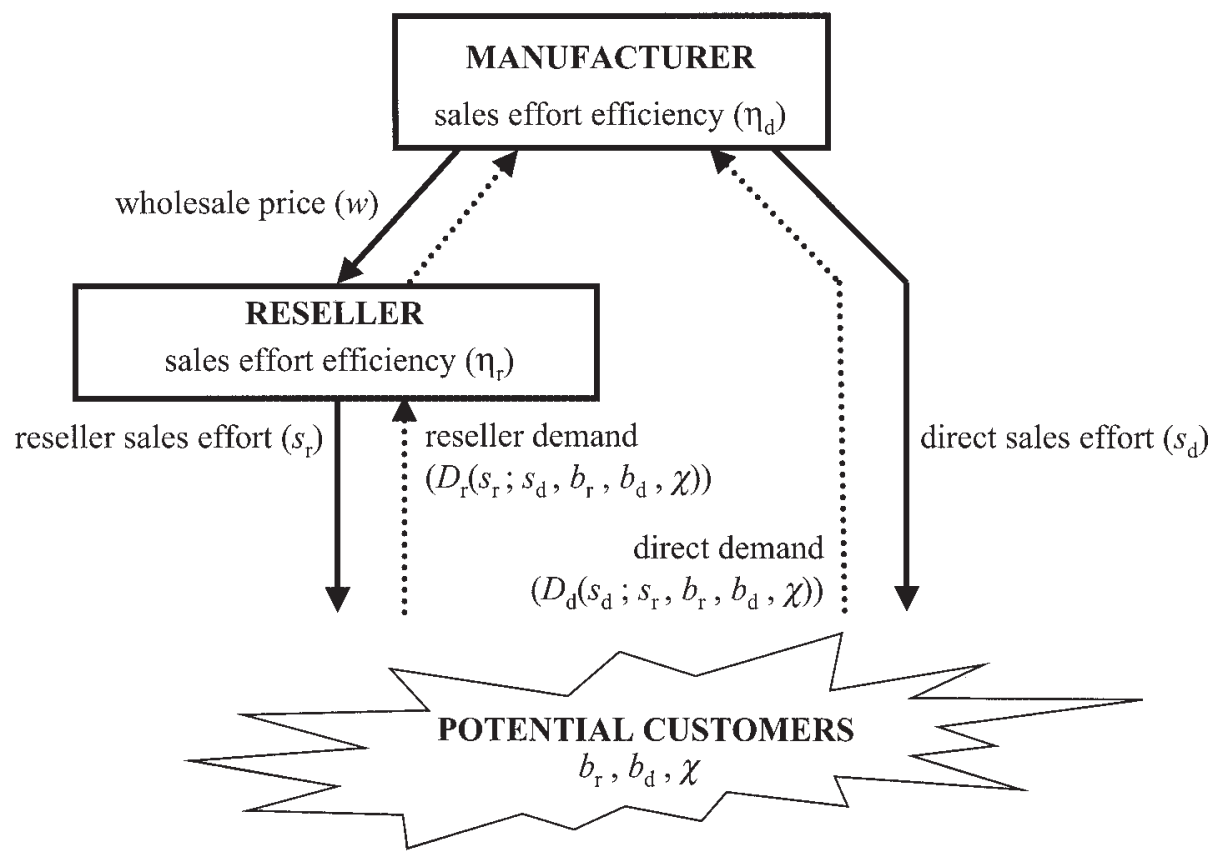

structure for B differs from that of $\mathrm{R}$ in that the manufacturer additionally determines $s_{d}$ (the relative timing of the determinations of $s_{d}$ and $s_{r}$ will turn out not to matter). To provide clarity in presenting our results, we define the following additional variables:

$$
\begin{gathered}
W \equiv p-\left((1-\chi) c_{r}+\chi \cdot c_{d}\right) \\
Y \equiv \frac{\eta_{d}\left(b_{r}\right)^{2}-\eta_{r}\left(b_{d}\right)^{2}}{2 \eta_{d}\left(b_{r}\right)^{2}-\eta_{r}\left(b_{d}\right)^{2}} \\
Z \equiv \frac{\eta_{d}\left(b_{r}\right)^{2}+\eta_{r}\left(b_{d}\right)^{2}}{2 \eta_{d}\left(b_{r}\right)^{2}-\eta_{r}\left(b_{d}\right)^{2}}
\end{gathered}
$$

$W$ represents the volume-weighted average profit to the system per unit sold in system $B$, while $Y$ and $Z$ have no obvious economic interpretations.

The outcomes for each system are tabulated in Table 2. This also includes as efficiency benchmarks the performance $\mathrm{R}$ and $\mathrm{B}$ could each achieve under central control. $^{9}$

These outcomes yield a number of insights. In DS, the sales effort is increasing in $\left(p-c_{d}\right)$, but decreasing in $\eta_{d}$. So the manufacturer simply seeks to balance the benefit received from selling product (the channel's profit margin on the product) against the cost of the effort expended in generating those sales.

When only the reseller channel is used (R), the sales

\footnotetext{
${ }^{9}$ Neither of these two benchmarks is uniformly more efficient than the other, as they differ in more than decision authority. In B, whether centrally controlled or not, some volume flows through the direct channel, whose manufacturing cost differs from that of the reseller channel.
}

effort is also increasing in the channel's unit profit margin $\left(p-c_{r}\right)$ and decreasing in $\eta_{r}$. This is the case whether or not the reseller is independent. However, under our modeling assumptions, an independent reseller will provide only half the amount of sales effort that central control would dictate. This is due to double marginalization, expressed in sales effort levels. ${ }^{10}$ As a result, $\mathrm{R}$ achieves only $75 \%$ of the profit available under central control.

When both channels are used (B), it is easy to show that the effort exerted in each channel is inefficiently low (as compared to B with central control). Due to the demand spillover across channels, in addition to the double marginalization within the reseller channel, neither firm individually perceives the full benefit that the system derives from local sales effort. Additional understanding of this arrangement may be obtained

\footnotetext{
${ }^{10}$ Double marginalization results from the existence of two independent entities within a distribution channel. In the classic setting of a manufacturer-retailer dyad facing a deterministic, downwardsloping demand curve (Spengler 1950), the retailer's choice of selling price $p$ represents a tradeoff between the unit profit margin (which favors higher $p$ ) and the volume of sales (which favors lower $p$ ). If the retailer pays the manufacturer a unit price $w$, which is strictly greater than the production $\operatorname{cost} c$, hence creating the two distinct profit margins referred to by the name of this phenomenon, the retailer's choice of $p$ will be consistent with a profit margin of ( $p$ $-w)$ rather than the $(p-c)$ that the system as a whole perceives. This distortion results in a retail price that is higher than would be globally optimal. Tsay and Agrawal (2000) have shown that double marginalization can be manifested in non-price dimensions as well, which, in our model, is too little sales effort from the reseller.
} 


\begin{tabular}{|c|c|c|c|c|c|}
\hline & DS & $\mathrm{R}$ & B & $\mathrm{R}$ with central control & B with central control \\
\hline Wholesale price & & $\frac{p+c_{r}}{2}$ & $p-Y \frac{W}{1-\chi}$ & & \\
\hline \multicolumn{6}{|l|}{ Sales effort } \\
\hline Reseller channel & & $\frac{p-c_{r}}{2 \eta_{r}}$ & $\frac{b_{r}}{\eta_{r}} Y W$ & $\frac{p-c_{r}}{\eta_{r}}$ & $\frac{b_{r}}{\eta_{r}} W$ \\
\hline Direct channel & $\frac{p-c_{d}}{\eta_{d}}$ & & $\frac{b_{d}}{2 \eta_{d}}(Y+Z) W$ & & $\frac{b_{d}}{\eta_{d}} W$ \\
\hline \multicolumn{6}{|l|}{ Demand } \\
\hline Reseller channel & & $\frac{p-c_{r}}{2 \eta_{r}}$ & $(1-\chi) \frac{\left(b_{r}\right)^{2}}{2 \eta_{r}}(Y+Z) W$ & $\frac{p-c_{r}}{\eta_{r}}$ & $(1-\chi)\left(\frac{\left(b_{r}\right)^{2}}{\eta_{r}}+\frac{\left(b_{d}\right)^{2}}{\eta_{d}}\right) W$ \\
\hline Direct channel & $\frac{p-c_{d}}{\eta_{d}}$ & & $\chi \frac{\left(b_{r}\right)^{2}}{2 \eta_{r}}(Y+Z) W$ & & $\chi\left(\frac{\left(b_{r}\right)^{2}}{\eta_{r}}+\frac{\left(b_{d}\right)^{2}}{\eta_{d}}\right) W$ \\
\hline Total demand & $\frac{p-c_{d}}{\eta_{d}}$ & $\frac{p-c_{r}}{2 \eta_{r}}$ & $\frac{\left(b_{r}\right)^{2}}{2 \eta_{r}}(Y+Z) W$ & $\frac{p-c_{r}}{\eta_{r}}$ & $\left(\frac{\left(b_{r}\right)^{2}}{\eta_{r}}+\frac{\left(b_{d}\right)^{2}}{\eta_{d}}\right) W$ \\
\hline \multicolumn{6}{|r|}{$\left(\eta_{r} \quad \eta_{d}\right)$} \\
\hline Reseller & & $\frac{\left(p-c_{r}\right)^{2}}{8 \eta_{r}}$ & $\frac{\left(b_{r}\right)^{2}}{2 \eta_{r}} Y Z W^{2}$ & & \\
\hline Manufacturer & $\frac{\left(p-c_{d}\right)^{2}}{2 \eta_{d}}$ & $\frac{\left(p-c_{r}\right)^{2}}{4 \eta_{r}}$ & $\frac{\left(b_{r}\right)^{2}}{4 \eta_{r}}(Y+Z) W^{2}$ & & \\
\hline Total profit & $\frac{\left(p-c_{d}\right)^{2}}{2 \eta_{d}}$ & $\frac{3\left(p-c_{r}\right)^{2}}{8 \eta_{r}}$ & $\frac{\left(b_{r}\right)^{2}}{4 \eta_{r}}[Y+Z+2 Y Z] W^{2}$ & $\frac{\left(p-c_{r}\right)^{2}}{2 \eta_{r}}$ & $\frac{1}{2}\left(\frac{\left(b_{r}\right)^{2}}{\eta_{r}}+\frac{\left(b_{d}\right)^{2}}{\eta_{d}}\right) W^{2}$ \\
\hline
\end{tabular}

Variables $W, Y$, and $Z$ are as defined in equations (4), (5), and (6).

by examining the impact of changing the various system parameters, as summarized in Table 3.

As would be expected, $\eta_{d}$ has a key role in determining the pattern of effort across the two channels at equilibrium. Any increase in $\eta_{d}$ curtails the manufacturer's effort, while the reseller effort grows, which is also the case when the channels are managed jointly. This reflects the reseller channel's increasing cost advantage in creating demand. Less obvious is what happens to profits. The manufacturer's profit is strictly decreasing in $\eta_{d}$, as one might suspect to result from an increase in the cost of direct sales effort. For low values of $\eta_{d}\left(<2\left(b_{d} / b_{r}\right)^{2} \eta_{r}\right)$, the reseller actually benefits from an increase in $\eta_{d}$ because the manufacturer shifts emphasis away from the direct channel by lowering the wholesale price. For $\eta_{d}<5\left(b_{d} / b_{r}\right)^{2} \eta_{r} / 4$, the reseller's benefit outweighs the manufacturer's loss, so that system profit increases with $\eta_{d}$. However, the general trend is that increasing $\eta_{d}$ reduces total demand since, on the whole, demand is becoming more costly to create, and this eventually dominates the former effect. For the centrally controlled benchmark, total profits strictly decrease with $\eta_{d}$ since this represents a systemwide increase in the cost of creating demand. The effect of increasing $\eta_{r}$ is entirely intuitive for both the independent and jointly managed system.

The effect of changes in $\chi$ in system $B$ is also enlightening. Recall that $\chi$ represents how much of the total demand the reseller loses to the direct channel.
As $\chi$ increases, the reseller's initial reaction is to provide less sales effort for any given wholesale price ${ }^{11}$ (per equation (9)), which hurts the manufacturer by reducing sales in both channels. To revive the reseller's interest, the manufacturer lowers the wholesale price. However, the extent to which the manufacturer is willing to do this is determined by the net value it places on the additional sales that the reseller can create. ${ }^{12}$ If the manufacturer's supply chain costs are lower in the direct channel, an increase in $\chi$ can best be exploited by increasing the volume in that channel, which necessitates a cut in the wholesale price. While the effect on the reseller channel's volume depends on the countervailing effects of the increase in effort and the increase in the proportion of customers claimed by the direct channel, the overwhelming benefit of the wholesale price reduction increases the reseller's profit. If, on the other hand, supply chain costs are higher in the direct channel, then the manufacturer is less willing to sacrifice its wholesale markup in the reseller channel to drive traffic to the direct channel,

${ }^{11}$ As evident from equation (9) in the Appendix, for a given wholesale price $w$, the reseller in R provides effort $\left(b_{r} / \eta_{r}\right)(p-w)$, while the effort of the reseller in B is only $(1-\chi)\left(b_{r} / \eta_{r}\right)(p-w)$.

${ }^{12}$ Denoting the equilibrium wholesale price in $\mathrm{B}$ as $w^{*}$, we have

$$
d w^{*} / d \chi=-\left[\left(\eta_{d}\left(b_{r}\right)^{2}-\eta_{r}\left(b_{d}\right)^{2}\right) /\left(2 \eta_{d}\left(b_{r}\right)^{2}-\eta_{r}\left(b_{d}\right)^{2}\right)\right]\left[\left(p-c_{d}\right) /(1-\chi)^{2}\right],
$$

whose magnitude is proportional to $\left(p-c_{d}\right)$. 


\begin{tabular}{|c|c|c|c|c|}
\hline & \multicolumn{4}{|c|}{ B } \\
\hline & $\uparrow \eta_{d}$ & $\uparrow \eta_{r}$ & $\uparrow \chi$ & $\uparrow c_{r}$ or $c_{d}$ \\
\hline Wholesale price & $\downarrow$ & $\uparrow$ & $\downarrow$ & $\uparrow$ \\
\hline \multicolumn{5}{|l|}{ Sales effort } \\
\hline Reseller channel & $\uparrow$ & $\downarrow$ & $\operatorname{sgn}\left(c_{r}-c_{d}\right)$ & $\downarrow$ \\
\hline Direct channel & $\downarrow$ & $\uparrow$ & $\operatorname{sgn}\left(c_{r}-c_{d}\right)$ & $\downarrow$ \\
\hline \multicolumn{5}{|l|}{ Demand } \\
\hline Reseller channel & $\downarrow$ & $\downarrow$ & $\operatorname{sgn}\left(-W+(1-\chi)\left(c_{r}-c_{d}\right)\right)$ & $\downarrow$ \\
\hline Direct channel & $\downarrow$ & $\downarrow$ & $\operatorname{sgn}\left(W+\chi\left(c_{r}-c_{d}\right)\right)$ & $\downarrow$ \\
\hline Total demand & $\downarrow$ & $\downarrow$ & $\operatorname{sgn}\left(c_{r}-c_{d}\right)$ & $\downarrow$ \\
\hline \multicolumn{5}{|l|}{ Profit } \\
\hline Reseller & $\operatorname{sgn}\left(2\left(b_{d} / b_{r}\right)^{2}-\eta_{d} / \eta_{r}\right)$ & $\downarrow$ & $\operatorname{sgn}\left(c_{r}-c_{d}\right)$ & $\downarrow$ \\
\hline Manufacturer & $\downarrow$ & $\downarrow$ & $\operatorname{sgn}\left(c_{r}-c_{d}\right)$ & $\downarrow$ \\
\hline \multirow[t]{3}{*}{ Total profit } & $\operatorname{sgn}\left(5\left(b_{d} / b_{r}\right)^{2} / 4-\eta_{d} / \eta_{r}\right)$ & $\downarrow$ & $\operatorname{sgn}\left(c_{r}-c_{d}\right)$ & $\downarrow$ \\
\hline & \multicolumn{4}{|c|}{ B with central control } \\
\hline & $\uparrow \eta_{d}$ & $\uparrow \eta_{r}$ & $\uparrow \chi$ & $\uparrow c_{r}$ or $c_{d}$ \\
\hline \multicolumn{5}{|l|}{ Wholesale price } \\
\hline \multicolumn{5}{|l|}{ Sales effort } \\
\hline Reseller channel & no effect & $\downarrow$ & $\operatorname{sgn}\left(c_{r}-c_{d}\right)$ & $\downarrow$ \\
\hline Direct channel & $\downarrow$ & no effect & $\operatorname{sgn}\left(c_{r}-c_{d}\right)$ & $\downarrow$ \\
\hline \multicolumn{5}{|l|}{ Demand } \\
\hline Reseller channel & $\downarrow$ & $\downarrow$ & $\operatorname{sgn}\left(-W+(1-\chi)\left(c_{r}-c_{d}\right)\right)$ & $\downarrow$ \\
\hline Direct channel & $\downarrow$ & $\downarrow$ & $\operatorname{sgn}\left(W+\chi\left(c_{r}-c_{d}\right)\right)$ & $\downarrow$ \\
\hline Total demand & $\downarrow$ & $\downarrow$ & $\operatorname{sgn}\left(c_{r}-c_{d}\right)$ & $\downarrow$ \\
\hline \multicolumn{5}{|l|}{ Profit } \\
\hline \multicolumn{5}{|l|}{ Reseller } \\
\hline \multicolumn{5}{|l|}{ Manufacturer } \\
\hline Total profit & $\downarrow$ & $\downarrow$ & $\operatorname{sgn}\left(c_{r}-c_{d}\right)$ & $\downarrow$ \\
\hline
\end{tabular}

Variable $W$ is defined in equation (4).

and also exerts less effort in that channel. Thus, total demand goes down, and the profits of both parties follow. The significance of this discussion is the insight into the behavioral dynamics surrounding multichannel interaction. Most noteworthy is that an increase in spillover of demand toward the direct channel may conceivably be desirable to both parties, as the induced reduction in wholesale price counteracts double marginalization.

When the system is centrally managed, the impact of $\chi$ on how profits are split is no longer relevant. However, $\chi$ still drives costs by determining the pattern of how demand is fulfilled, since the two channels have different operations efficiencies. Total profits increase with $\chi$ if and only if $c_{r}>c_{d}$, since increasing the direct channel's share of demand is beneficial only when that channel is more efficient logistically. When this is the case, sales efforts in both channels are increased to generate greater total demand.

Finally, increasing the supply chain cost in either channel $\left(c_{r}\right.$ or $\left.c_{d}\right)$ reduces both parties' profits. This is natural for the manufacturer since it is directly exposed to both these costs. For the reseller, the dependence is through the manufacturer's specifi- cation of wholesale price, and also the reliance of reseller sales on the effort in the direct channel. The explanation of this effect in the centrally managed case is obvious.

\subsection{The Manufacturer's Channel Strategy Preferences}

The manufacturer ultimately seeks a channel strategy. In Proposition 1, we determine the option that maximizes the manufacturer's profits. This choice is affected by the relative supply chain costs $\left(c_{d}\right.$ vs. $\left.c_{r}\right)$ and the comparative advantage in efforts that create sales (as reported by the ratio $\eta_{d} / \eta_{r}$, for which larger values indicate a greater advantage for the reseller channel, or equivalently a disadvantage for the direct channel).

Proposition 1. The manufacturer's preference across systems can be stated as follows, with $W$ as defined in (4) [X $\succ Y$ means that system $X$ provides greater profits than does system $Y]$ :

(a) $B \succ R$ if and only if $\eta_{d} / \eta_{r}<\frac{1}{2}\left(b_{d} / b_{r}\right)^{2}\left[1-\left(W b_{r} /(p\right.\right.$ $\left.\left.\left.-c_{r}\right)\right)^{2}\right]^{-1} \equiv N^{B, R}$.

(b) $B>D S$ if and only if $\eta_{d} / \eta_{r}>\left(b_{d} / b_{r}\right)^{2}[1$ $\left.-\sqrt{1-\left(W b_{d} /\left(p-c_{d}\right)\right)^{2}}\right]^{-1} \equiv N^{D S, B}$ 
(c) $R>D S$ if and only if $\eta_{d} / \eta_{r}>2\left[\left(p-c_{d}\right) /\left(p-c_{r}\right)\right]^{2}$ $\equiv N^{D S, R}$

Part (a) suggests that a manufacturer currently using only the reseller channel would do better to also sell direct if the direct channel enjoys a supply chain efficiency advantage, or if the manufacturer's disadvantage in selling is not "too large," as defined by $N^{B, R}$. $N^{B, R}$ is decreasing in both $c_{d}$ and $\chi$, meaning that adding a direct channel becomes harder to justify with an increase in either its supply cost requirement or the extent to which it will divert demand from resellers. Similarly, part (b) suggests that a manufacturer currently selling only directly should consider adding reseller distribution if the manufacturer's disadvantage in selling is sufficiently large. Here, the threshold $N^{D S, B}$ is increasing in both $c_{r}$ and $\chi$. Adding the reseller to the mix becomes harder to justify as the reseller channel's supply chain cost increases, as one would expect. Likewise, because of the reseller's need to be compensated for demand lost to the direct channel, a large $\chi$ means that what the reseller has to offer in terms of selling advantage must be that much more compelling for the manufacturer to add this channel. Finally, part (c) provides the intuitive result for the comparison between the single-channel strategies: the reseller channel alone is preferable if it has a sufficiently large advantage in selling, where the threshold is raised as that channel's supply chain cost is increased.

A key implication of Proposition 1 is that, in general, there is no strict dominance among the three strategies. We illustrate this in Figures 2 and 3, which depict the manufacturer's ranking of the strategies for two separate numerical examples differing in how the total market size changes when a second channel is added. Both examples use $\left(c_{r}=5, p=15, \eta_{r}=1, \chi\right.$ $=0.6)$, while Figure 2 has $b_{r}=b_{d}=1$ and Figure 3 has $b_{r}=b_{d}=0.8$. Thus, the multi-channel strategy is

Figure 2 Manufacturer's Preferences with No Market Overlap $\left(b_{r}=b_{d}=1\right)$

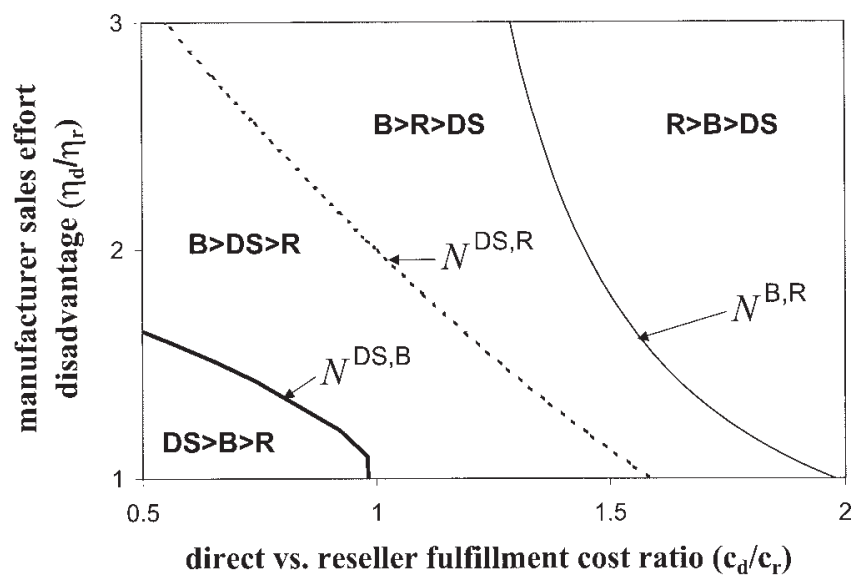

Figure 3 Manufacturer's Preferences with Market Overlap $\left(b_{r}=b_{d}=0.8\right)$

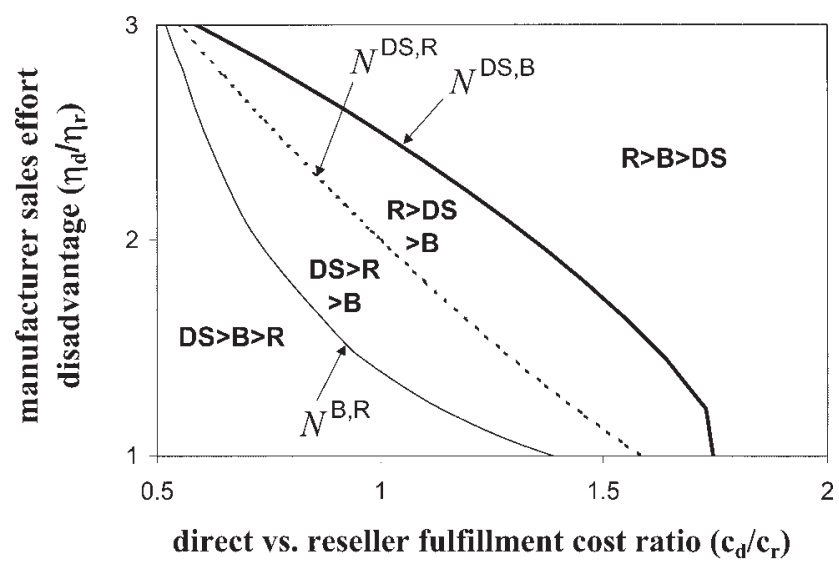

relatively more effective at increasing the total market in Figure 2 than in Figure 3, all else equal. Another way to explain this is that there is greater overlap in the markets addressed by the respective channels in Figure 3. This is separate from the phenomenon represented by $\chi$, which is how that demand is split between channels.

The segmentation of the $\left(c_{d} / c_{r}, \eta_{d} / \eta_{r}\right)$ plane into regions is generally intuitive. Starting from the lower left region, increasing $\eta_{d} / \eta_{r}$ or $c_{d} / c_{r}$ is disadvantageous to the direct channel, driving the manufacturer's preferred channel strategy away from direct-only (DS). When either or both of the metrics become sufficiently large, the manufacturer should abandon direct sales and distribute through the reseller (R). Taking this logic in the reverse direction, a manufacturer that is able to achieve low values of both ratios (i.e., it can generate customers almost as cost-effectively through the direct channel, and fulfill that demand with cost that compares favorably to that of the reseller channel) should use only the direct channel. This seems to corroborate the business model of Dell Computer, for instance. With its adeptness at enticing customers to buy direct via the World Wide Web or telephone (low $\eta_{d}$ ), and its well-known supply chain efficiencies (low $c_{d}$ ), Dell has become one of the most formidable and envied players in the PC industry (notably, without being the lowest price vendor) (Magretta 1998). What happens in between these two extremes depends on the extent of market overlap. Figure 2 demonstrates the existence of scenarios under which a manufacturer is wise to use both channels: the reseller channel is retained for its selling capability since $c_{d}$ is not low enough to offset the manufacturer's $\eta_{d}$, and the direct channel is retained because $\eta_{d}$ is low enough to justify using direct sales effort to drive business to both channels. The transition to Figure 3 suggests that the more the second channel tends to shift existing customers rather than reach new customers, 
the less attractive a dual-channel strategy will be. Instead, the manufacturer should use either direct sales or resellers exclusively.

4.2. The Reseller's Channel Strategy Preferences An equally important issue is the reseller's preferences for R vs. B (DS is excluded since the reseller plays no role in that strategy), as described in Proposition 2.

Proposition 2. The reseller prefers $R$ to $B$ when

$$
c_{d}>c_{r}-\frac{\left(p-c_{r}\right)}{\chi}\left(\frac{1}{2 b_{r} \sqrt{Y Z}}-1\right)
$$

(with variables $Y$ and $Z$ as defined in equations (5) and (6)).

Figures 4 and 5 illustrate this result for the same parameter values as in Figures 2 and 3.

One might conjecture, in light of concerns about channel conflict, that the reseller would always prefer $\mathrm{R}$ to $\mathrm{B}$. However, we have shown this not to be true at all. For the given parameter combinations, the reseller does better as part of a dual channel strategy when $c_{d}$ is relatively low because this motivates the manufacturer to charge a low wholesale price (to exploit the reseller's ability to drive sales in both channels). The fact that the boundary between the regions bends backwards is related to the dynamic revealed in the comparative statics for $\eta_{d}$ in system B, presented in Table 3: after a certain point, increases in $\eta_{d}$ hurt the reseller because the manufacturer finds the cost of providing sales effort prohibitive. Naturally, the cases in which B is preferable shrinks in going from Figure 4 to Figure 5.

Significantly, there is overlap in the regions in Figures 2 and 4 in which $B$ is preferred by each party. This illustrates that both parties can benefit when the manufacturer adds direct sales to a previously resellerfocused strategy. (This depends, of course, on the particular parameters used.) This effect is not present in Figures 3 and 5, however, as the reduction in the total market accessible by the dual-channel approach

Figure 4 Reseller's Preferences with No Market Overlap $\left(b_{r}=b_{d}=1\right)$

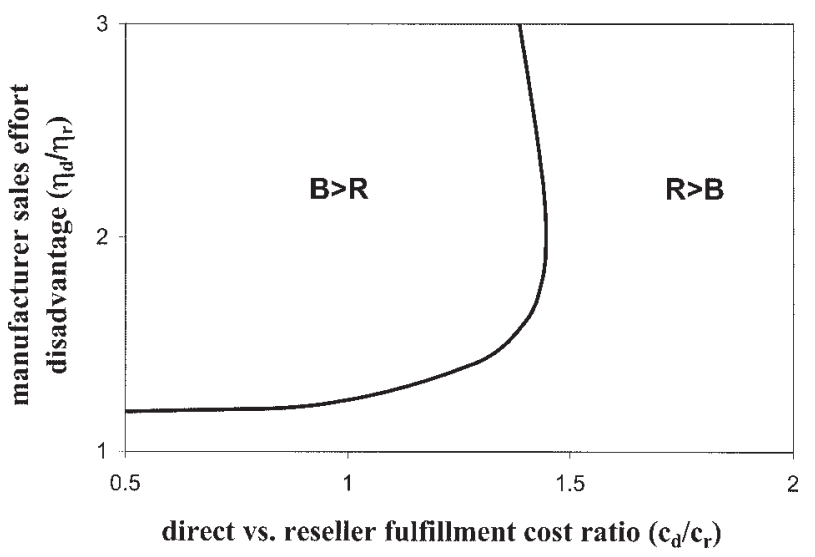

Figure 5 Reseller's Preferences with Market Overlap $\left(b_{r}=b_{d}=0.8\right)$

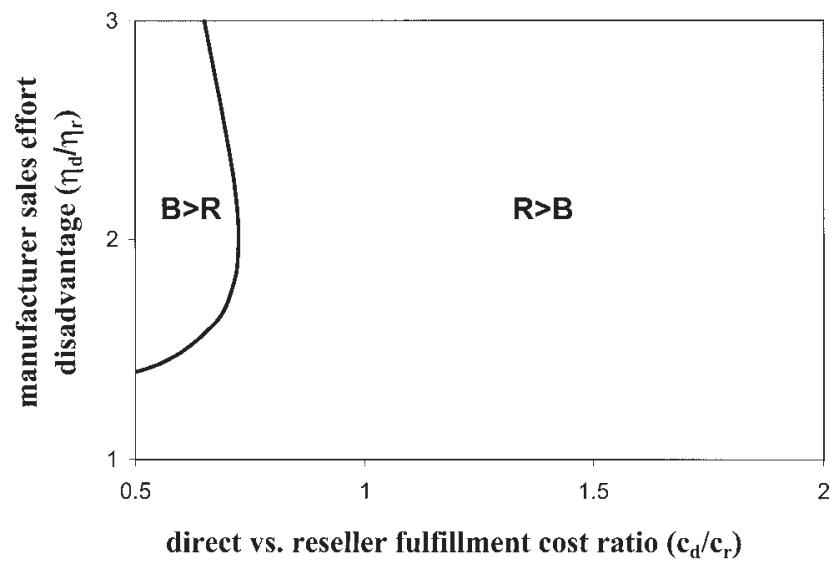

makes B less desirable to both parties. Figures 3 and 5 do confirm a surprising finding that was also present in Figures 2 and 4: even when the manufacturer explicitly prefers to sell only through the reseller (this requires $\eta_{d}$ to be relatively large, meaning that the reseller is a more effective way to create demand), the reseller may prefer that the manufacturer open a direct channel in parallel (this requires that $c_{d}$ not be too large relative to $c_{r}$, since otherwise the reseller will be overly penalized by the manufacturer's adjustments for the fulfillment inefficiency of the direct channel). ${ }^{13}$ This can occur because a reseller that is sufficiently important to the manufacturer for sales effort purposes would need to be significantly compensated for the presence of a direct channel via a concession in the wholesale price. We have thus identified another dimension of channel conflict regarding the prospect of multi-channel distribution, with the parties lined up on sides opposite than typically expected.

\section{Incentive Schemes For Multi- Channel Distribution}

We know from the previous section that whether the reseller channel is used in isolation or in parallel to a direct channel, independent decision-making by the two firms leads to system inefficiency, and we have identified the causes. The reseller-only setting has certainly been the subject of much study, and its efficiency characteristics are fairly well understood. For instance, a number of works have shown that schemes with quantity discount or two-part tariff structure enable coordination under a variety of settings (cf. Jeuland and Shugan 1983; Moorthy 1987; Desiraju and Moorthy 1997).

We thus focus attention on system B, considering a manufacturer that has chosen to use both channels for

\footnotetext{
${ }^{13}$ In Figures 2 and 3, this is a small but distinct segment in the upper left of the manufacturer's R-favoring region.
} 
strategic reasons. (Consider, for instance, the former Compaq's dual channel strategy described in Section 1, generally assumed to be a reaction to Dell.) Our objective here is to investigate whether the performance of such a system can be enhanced by modifying the terms of the business relationship between the manufacturer and the reseller. Following the lead of the literature on coordination of a reseller-only system, we consider generalizing the pricing terms for the reseller's wholesale purchase beyond the simple form used in our preceding analysis. We will then examine two other schemes that are observed in practice. The first is a concept proposed by Compaq in 1998 as a way to maintain harmony among its resellers-offering them a percent commission for referring customers to the direct channel (McWilliams 1998). The second is a stylized representation of the practice followed by companies such as IBM (Girishankar 1998), Hewlett-Packard, and Travelocity (Machlis 1998a) - referring all customers to a channel intermediary that then profits by handling the fulfillment function. For each scheme, we will comment on the implications for local behavior and the allocation of profits.

\subsection{Generalized Wholesale Pricing}

Consider system $B$ with one modification: the total wholesale payment is a general function $H(Q, s)$ that reflects the order quantity and the reseller's sales effort. While such a scheme may be impractical for a variety of reasons (e.g., the reseller's effort may be difficult to monitor), it provides a number of insights and a basis for subsequent discussion of more workable schemes. By analysis similar to the preceding, we can determine the reseller's behavior as a function of $H($ ). The efficiency question is then whether proper specification of $H()$ can induce the sales effort in each channel that would be optimal if B were centrally controlled.

Proposition 3 provides conditions a general $H(Q, s)$ must meet if it is to coordinate the fully independent system, then comments on the implications of pursuing a more easily implementable linear form. We use asterisks to identify the sales effort and demand levels in each channel that a central planner would choose (i.e., $s_{r}^{*}, s_{d}^{*}, D_{r}^{*}$, and $D_{d}^{*}$ ), whose explicit values are reported in the rightmost column of Table 2. These depend on the marketing and supply chain cost characteristics, but not the wholesale payment (which is a transfer internal to the system). We also abbreviate $\partial H(Q, s) / \partial Q$ and $\partial H(Q, s) / \partial s$ as $H_{Q}^{\prime}(Q, s)$ and $H_{s}^{\prime}(Q, s)$, respectively.

Proposition 3. Coordinating dual channels via wholesale pricing:

(a) A schedule $H(Q, s)$ achieves coordination if and only if it satisfies the following conditions:

$$
H_{Q}^{\prime}\left(D_{r}^{*}, s_{r}^{*}\right)=p
$$

$$
H_{s}^{\prime}\left(D_{r}^{*}, s_{r}^{*}\right)=-W b_{r}
$$

(variable $W$ is defined in equation (4)).

(b) No schedule that depends on quantity only (i.e., has the form $H(Q))$ can achieve coordination.

The proposal in (a) is easily interpretable based on the causes of inefficiency. As established earlier, the dual channel arrangement is inefficient because the reseller does not perceive the same benefit from providing sales effort as does the system as a whole. The distortion is due to both double marginalization and the spillover of demand across channels, so that the reseller's cost-benefit calculation leads to too little effort. The condition in (7) neutralizes the spillover issue since, with zero reseller markup, the reseller becomes indifferent to where the marginal customer goes. Double marginalization is addressed by (8), which pays the reseller exactly the benefit that accrues to the system from sales generated by the marginal unit of reseller effort. (The negative sign on the right side of (8) in effect applies credits to the reseller's wholesale payment for increases in sales effort.) Hence, this scheme imposes on the reseller the precise (marginal) economics of the system.

Of course, this does not explicitly specify how the efficiency gain will be allocated among the parties, which is central to implementation. Further specification of the form of $H$ is required for such a discussion. For instance, the simplest way to implement the above pricing scheme would be the linear form $H(Q, s)=p Q$ - $W b_{r} s$. This would deliver profit of $\left(W b_{r}\right)^{2} /\left(2 \eta_{r}\right)$ to the reseller and $\left(W b_{d}\right)^{2} /\left(2 \eta_{d}\right)$ to the manufacturer. ${ }^{14}$ Relative to the profit outcomes reported for B in Table 2 , this is better for the reseller but worse for the manufacturer. So, even though this method produces an efficiency gain, some additional transfer of funds might be necessary to motivate its use by the manufacturer. One way to achieve would be to include a lump-sum term in $H(Q, s)$.

As noted, sales effort provided by an independent reseller may be difficult for the manufacturer to monitor in practice, so wholesale price schedules conditioned on this may simply be untenable. Therefore, we consider in part (b) whether pricing schemes that depend only on $Q$ can be sufficient for coordination. We find that, in general, no form of $H(Q)$, no matter how complex, can achieve coordination when channel interaction is present. Mechanisms of this class simply possess too few independent degrees of freedom to guide the reseller and the manufacturer effort levels simultaneously to the system-optimal choices. We

\footnotetext{
${ }^{14}$ By Proposition 3, this wholesale pricing scheme achieves the sales effort and demand levels reported in Table 2 for B with Central Control. Substituting these into (10) and (11) delivers the stated result.
} 
Table 4

Equilibria for Referral Schemes (RD and RR)

\begin{tabular}{lcc}
\hline Wholesale price & Referral to direct (RD) & Referral to reseller (RR) \\
Referral commission & $Y \frac{p-c_{d}}{p(1-\chi)}$ & $p-Y\left(p-c_{r}\right)$ \\
Sales effort & $\frac{b_{r}}{\eta_{r}} Y\left(p-c_{d}\right)$ & $\frac{b_{r}}{\eta_{r}} Y\left(p-c_{r}\right)$ \\
\multicolumn{1}{l}{ Reseller channel } & $\frac{b_{d}}{2 \eta_{d}}(Y+Z)\left(p-c_{d}\right)$ & $\frac{b_{d}}{2 \eta_{d}}(Y+Z)\left(p-c_{r}\right)$ \\
Direct channel & $\frac{\left(b_{r}\right)^{2}}{2 \eta_{r}}(Y+Z)\left(p-c_{d}\right)$ & $\frac{\left(b_{r}\right)^{2}}{2 \eta_{r}}(Y+Z)\left(p-c_{r}\right)$ \\
Demand & $\frac{\left(b_{r}\right)^{2}}{2 \eta_{r}}(Y+Z)\left(p-c_{d}\right)$ & $\frac{\left(b_{r}\right)^{2}}{2 \eta_{r}}(Y+Z)\left(p-c_{r}\right)$ \\
Reseller channel & $\frac{\left(b_{r}\right)^{2}}{2 \eta_{r}} Y Z\left(p-c_{d}\right)^{2}$ & $\frac{\left(b_{r}\right)^{2}}{2 \eta_{r}} Y Z\left(p-c_{r}\right)^{2}$ \\
Total demand & $\frac{\left(b_{r}\right)^{2}}{4 \eta_{r}}(Y+Z)\left(p-c_{d}\right)^{2}$ \\
Profit & $\frac{\left(b_{r}\right)^{2}}{4 \eta_{r}}(Y+Z+2 Y Z)\left(p-c_{d}\right)^{2}$ \\
Reseller & $\frac{\left(b_{r}\right)^{2}}{4 \eta_{r}}(Y+Z)\left(p-c_{r}\right)^{2}$ \\
Manufacturer & $(Y+Z+2 Y Z)\left(p-c_{r}\right)^{2}$ \\
\hline
\end{tabular}

Variables $Y$ and $Z$ are as defined in equations (5) and (6).

thus turn our attention to alternative schemes which are feasible to implement. ${ }^{15}$

\subsection{Referral Schemes}

As noted earlier, we consider the following two methods that refer all customers to one of the channels for demand fulfillment:

$R D$ ("Referral to Direct"): In this arrangement, the reseller markets the product but customers ultimately purchase from the manufacturer. For instance, the showroom floor may display only samples for customers to experience, perhaps under the auspices of knowledgeable salespeople who then can assist the customers in placing direct orders with the manufacturer. The reseller then effectively becomes the manufacturer's sales agent, with no role in and therefore no profit from the actual fulfillment of demand. For providing this service, the reseller receives a fraction $\beta$ of the selling price as a commission, the sole incentive

${ }^{15}$ Although they cannot restore full system efficiency, quantity-only schemes are not without merit. Under certain conditions, these may yet facilitate outcomes that are Pareto-superior to system R, thus ensuring the reseller's consent to a dual-channel arrangement. Deriving such a scheme involves adding a constraint to the manufacturer's optimization problem that states that both parties must receive at least what they receive under system R. Unfortunately, this defies closed-form characterization. While we have obtained such schemes numerically for certain parameter combinations, they are not guaranteed to exist in general. for the reseller to provide sales effort. ${ }^{16}$ For the sake of simplicity, we assume the implementation is such that the customers are rendered indifferent to the mode of purchase, and therefore that the total demand is unaffected by the act of referral. As noted earlier, we also assume that the selling price covers any shipping charges.

$R R$ ("Referral to Reseller"): In this alternative, the reseller has exclusive rights to fulfill all demand. The direct channel thus serves only as a source of information, advertisement, and other pre-sales service/ advice. This seeks to counteract channel conflict by allowing the reseller a cut of every unit sold. As in the $\mathrm{RD}$ setting, we assume that the customers are indifferent to the mode of purchase, and therefore that the total demand is unaffected by the location of fulfillment.

The equilibrium for each scheme, displayed in Table 4 , may be obtained by analysis similar to that used for system B.

Our first observation is the similarity of these equilibria to that displayed in Table 2 for system B. This is

\footnotetext{
${ }^{16}$ There may be other reasons an intermediary might wish to develop a relationship with the end customer even if no profit is obtained on the initial sale. For instance, Cohen and Whang (1997) note that the bulk of profits earned by car dealerships results from after-sale service and parts. Such issues are not considered in our model.
} 
in part due to the simplifying assumptions of our model, but also reveals that the alternative methods do share certain underlying structural characteristics, which will become evident below.

The fundamental question is whether the RD or RR schemes can improve the profits of both parties relative to $B$, and therefore provide a viable means to implement a multi-channel distribution strategy. This is addressed in Proposition 4.

Proposition 4. Both parties (and therefore the system as a whole) have the following preferences: $c_{d}<c_{r}$ implies $R D \succ B \succ R R$, while $c_{r}<c_{d}$ implies $R R \succ B \succ R D$.

This ordering seems reasonable with respect to the total profit, in that net benefit to the system is tied to the cost of fulfilling demand. The fundamental economic leverage shared by the alternative schemes is in achieving a division of labor according to each channel's competitive advantage: customers are obtained using the most cost-effective combination of channel efforts and served using the most cost-effective method (which is determined by the relative magnitudes of $c_{d}$ and $c_{r}$ ). When $c_{d}<c_{r}$, it is best for the reseller to be removed from the business of fulfillment altogether and to focus on stimulating demand. When $c_{r}>c_{d}$, the reseller has the advantage in both fulfillment and selling, and should thus be the centerpiece of the distribution strategy. In this scenario, the direct channel's role is only to drive traffic to reseller channel.

Less obvious is that both the manufacturer and reseller should be of one voice on the matter, which reflects the willingness of the manufacturer to share the efficiency gains. The reseller's preferences can be explained in terms of the cash value of each customer. In $\mathrm{B}$, every customer the reseller brings to the system is worth $Y(W /(1-\chi))$ to the reseller in collected markup. Meanwhile, the RD scheme is such that, at equilibrium, the manufacturer is willing to pay $Y((p$ $\left.\left.-c_{d}\right) /(1-\chi)\right)$ in commission dollars for every customer. And in RR, the reseller earns a markup of $Y(p$ $\left.-c_{r}\right)$ on every customer, which translates to $Y((p$ $\left.\left.-c_{r}\right) /(1-\chi)\right)$ for each of the customers the reseller would have attracted absent the referral. (This is identical to the value in B when $\chi=0$, which is not surprising as RR attempts to eliminate the source of the reseller's explicit opposition to direct sales.) Since the cost structure for sales effort is the same under all arrangements, the reseller simply prefers the one under which it earns the most per customer. In turn, the manufacturer shares these preferences since a greater value per customer impels the reseller to provide more effort, which increases the flow of customers to the direct channel. In fact, these preferences are independent of $\eta_{d}$ and $\eta_{r}$, meaning that the RD and RR schemes are robust to the extent of the imbalance in selling capability. So, if there are gains to be had from an appropriate division of labor, the manufacturer is always willing and able to compensate the reseller to participate.

We also note that the basic B strategy is never dominant when the RR and RD options are both available. This is reminiscent of the "bang-bang" property (extreme-point solution) of certain optimization models in that demand is best handled entirely by the cheapest source, which is the essence of B's main shortcoming. This is true even without considering any diseconomies of scope that would further plague a strategy in which both parties attempt to serve both functions, or economies of scale that should accrue from consolidating all materials flow into one channel. Of course, the rank ordering might be different with customers sensitive to the availability of purchase options, which we do not explicitly model.

The implication for a company such as the former Compaq (and, by extension, its channel partners) is that, given a decision to use both channels, the RD scheme should be used in lieu of the conventional linear wholesale price arrangement only if the supply chain cost in the direct channel can be made lower than the cost for reseller sales. If this is not possible, then the proper response to channel conflict is to leave all fulfillment to an intermediary and use the direct efforts only to drive traffic to that channel, as IBM, Hewlett-Packard, and Travelocity have done. Indeed, Compaq itself relied on this strategy for almost its entire history prior to this new initiative. But either way there exists a means to Pareto-improve the performance of all parties in a dual-channel system without compromising local autonomy in decision-making. Furthermore, this can be achieved without the need to monitor the independent reseller's sales effort, which, as noted in the discussion of Proposition 3, may be very costly or even impossible to do. At least within the assumptions of our model, making this decision depends only on factors the manufacturer can observe and control (i.e., the relative values of $c_{d}$ and $c_{r}$ ).

Our findings are consistent with the attitude reflected in Hewlett-Packard's program, in which credit for an online sale is awarded to both the business account's assigned sales representative as well as HP's fulfillment partner. Vikram Mehta, Worldwide Marketing Manager for HP's Enterprise Accounts organization, notes, "Our all-channel strategy is centered around the issue of separating out demand creation from demand fulfillment. We compensate people for what we ask them to do to create demand and don't worry how that demand is fulfilled" (Garner 1999). This logic may also be reasonable from the reseller's perspective. James McQuivey of Forrester Research 
notes that, while Home Depot's policy (reflected in the warning letter described in Section 1) may be totally fair, it is shortsighted. Instead, Home Depot could easily convince manufacturers that they do not want to have to build their own fulfillment centers for online sales when Home Depot is better positioned to fill product orders: "We keep our customer, you sell your product" (Goldman 1999).

Finally, while we have not focused on the perspective of the end customers, we observe that they should also favor whichever system is preferable to the two firms. This is because the rank ordering in sales effort (which is presumably beneficial to the customers) parallels the ordering in each firm's profit, and purchase price is held constant across the schemes.

\section{Concluding Remarks}

A number of factors, including recent developments in Internet-based commerce and the transformation of shipping economics driven by the growth of the thirdparty logistics industry, have led many companies to consider engaging in direct sales. This may put such companies in competition with their existing reseller partners. The potential channel conflict has momentous implications for distribution strategy, and is the main focus of this paper.

With the goal of generating managerial insights into this issue of import, we have developed a simple model that captures key attributes of the relationship between a manufacturer and a reseller who act independently, including various sources of inefficiency. These include double marginalization within the reseller channel, and the failure of each channel to fully perceive the positive externality that its sales efforts can have on the other channel. The latter is directly related to the issue of channel conflict, whose formalization is a central contribution of this research. We have examined these concerns in detail, determining the resulting behaviors and profit outcomes and identifying a number of counterintuitive structural properties.

Contrary to expectation, the addition of a direct channel alongside a reseller channel is not necessarily detrimental to the reseller. In fact, the manufacturer will reduce the wholesale price to retain some of the reseller's selling effort, and in some cases, this can make both parties better off. There can be a net system-wide efficiency gain to share because the wholesale price reduction can counteract double marginalization. Moreover, within such a dual-channel arrangement, diverting product flow to the direct channel can create efficiency gains if this serves demand at lower overall supply chain cost. Hence, the reseller's concern may, in reality, be groundless. In general, the desirability to each party of the distribu- tion options depends on how the channels compare in terms of both supply chain efficiency and marketing capability, and none of the strategies we have examined is universally preferred by either party. In fact, we have found circumstances in which the conventional expectation is reversed: the manufacturer favors using only the reseller, but the reseller prefers that the manufacturer open a direct channel in parallel.

We have extended the literature on channel coordination to a setting in which the upstream party is at once a supplier to and a competitor of the downstream party. We have found that revisiting the wholesale pricing terms can improve the overall efficiency of a dual-channel system. However, the greatest improvements are realized when the pricing is premised on the reseller's sales effort, which may be difficult or impossible to monitor in practice. Our attention then turned to other schemes observed in industry that do not have this requirement. These include paying the reseller a commission for diverting all customers toward the direct channel (RD), or conceding the demand fulfillment function entirely to the reseller (RR). Such schemes could in fact be more profitable for both parties in that they achieve a division of labor according to each channel's competitive advantage: customers are obtained using the most cost-effective combination of channel efforts (as determined by $\eta_{d}, \eta_{r}, b_{d}$, and $b_{r}$ ) and served using the most cost-effective method (which is determined by the relative magnitudes of $c_{d}$ and $c_{r}$ ).

Our analysis suggests numerous opportunities to further generalize this important line of inquiry. For example, a deeper understanding of the role of inventory could be attained by explicitly modeling demand uncertainty. This would also allow consideration of another potential advantage enjoyed by a direct channel-better access to demand information. Section 1 mentions other less tangible tradeoffs between direct and intermediated selling that are not directly captured in our objective functions, including issues of image control, flexibility, and brand loyalty. The static (single-period) nature of our framework also has limitations. For instance, a manufacturer may use reseller distribution to build market share for a new product, even if this compromises short-term profit. The evolution of distribution strategy over the life cycle of a product appears to be an open research area.

As is the case in much of this literature, our consideration of customer behavior has been at a fairly aggregate level. Future research could model in greater detail the drivers of customer channel preference, which can include attitudes toward (or the economic consequences of) factors such as product customization, delivery lead times, ease of returns, etc. 


\section{Acknowledgments}

This research was supported by Santa Clara University through a Junior Faculty Fellowship and a grant from the Retail Management Institute. Colin Kessinger and Shelby McIntyre provided useful comments on a previous version of this manuscript.

\section{Appendix}

\section{Derivation of Expressions in Table 2}

We begin with system $B$ since system $R$ turns out to be a special case of system B. In system B, the reseller's profit is $\pi_{R}\left(s_{r}\right)=(p-w)(1-\chi)\left(b_{r} s_{r}+b_{d} s_{d}\right)-\eta_{r} s_{r}^{2} / 2$, maximized at

$$
\hat{s}_{r}(w)=(1-\chi) b_{r}(p-w) / \eta_{r} .
$$

The manufacturer's profit is then $\pi_{M}\left(s_{d}, w\right)=\left(w-c_{r}\right)(1$ $-\chi)\left(b_{r} \hat{s}_{r}(w)+b_{d} s_{d}\right)+\left(p-c_{d}\right) \chi\left(\hat{s}_{r}(w)+b_{d} s_{d}\right)-\eta_{d} s_{d}^{2} / 2$. For the manufacturer's problem, the Hessian is

$$
\left|\begin{array}{cc}
-\eta_{d} & (1-\chi) b_{d} \\
(1-\chi) b_{d} & -2 b_{r}(1-\chi)^{2} / \eta_{r}
\end{array}\right|
$$

so the profit function is strictly concave if $2 \eta_{d}\left(b_{r}\right)^{2} / \eta_{r}-\left(b_{d}\right)^{2}$ $>0$, which is assured by (1). The first order conditions then yield the wholesale price and direct sales effort, and hence the system B equilibrium, presented in Table 2 .

The system $R$ equilibrium may be obtained from the system $B$ equilibrium by setting $\chi=0$ (so that $W=p-c_{r}$ ), $b_{r}=1$, and $b_{d}=0$. For the DS system, the appropriate parameter setting is $\chi=1, b_{r}=0$, and $b_{d}=1$. Note that this equilibrium cannot be obtained from the $\mathrm{B}$ equilibrium directly since certain steps of solving the first order conditions are no longer valid. Instead, we use these parameter values in the first-order conditions and solve from that point on.

System $\mathrm{R}$ with central control is structurally equivalent to DS, except replacing $\eta_{d}$ and $c_{d}$ with $\eta_{r}$ and $c_{r}$, respectively. In system B with central control, the total system profit may be written as $\pi_{T}\left(s_{r}, s_{d}\right)=W\left(b_{r} s_{r}+b_{d} s_{d}\right)-\eta_{r} s_{r}^{2} / 2-\eta_{d} s_{d}^{2} / 2$. The first-order conditions, which are clearly sufficient for a global maximum, yield the sales effort levels presented in Table 2. The remaining expressions for this system follow directly.

Proof of Propositions 1 and 2. These results follow directly from pair-wise comparison of the appropriate profit expressions by channel strategy, as listed in Table 2.

Proof of Proposition 3. For this scheme, the profits are

$$
\begin{gathered}
\pi_{R}=p \cdot D_{r}-H\left(D_{r}, s_{r}\right)-\eta_{r} s_{r}^{2} / 2 \\
\pi_{M}=H\left(D_{r}, s_{r}\right)-c_{r} \cdot D_{r}+\left(p-c_{d}\right) D_{d}-\eta_{d} s_{d}^{2} / 2
\end{gathered}
$$

For the reseller's problem,

$$
\begin{array}{r}
d \pi_{R} / d s_{r}=(1-\chi) b_{r}\left(p-H_{Q}^{\prime}\left(D_{r}, s_{r}\right)\right) \\
\quad-H_{s}^{\prime}\left(D_{r}, s_{r}\right)-\eta_{r} s_{r}
\end{array}
$$

and for the manufacturer,

$$
\begin{aligned}
d \pi_{M} / d s_{d}=(1-\chi) b_{d}\left(H_{Q}^{\prime}\left(D_{r}, s_{r}\right)\right. & \left.-c_{r}\right) \\
& +\chi b_{d}\left(p-c_{d}\right)-\eta_{d} s_{d}
\end{aligned}
$$

We assume additional second-order conditions to ensure each firm's first-order condition is sufficient for profit maximization. This is not restrictive due to the generality we allow for the functional form of $H($ ).

Let us use "hats" on the variables to represent the equilibrium outcome for a given $H(Q, s)$ (i.e., $\hat{s}_{r}, \hat{s}_{d}, \hat{D}_{r}$ and $\left.\hat{D}_{d}\right)$, and "stars" to denote the optimal solution for B under central control. Supposing that the reseller sets $\hat{s}_{r}=s_{r}^{*}$, we can see from (12) and (13) and some algebra that if the manufacturer chooses $\hat{s}_{d}=s_{d}^{*}$ (so that $\hat{D}_{r}=D_{r}^{*}$ and $\hat{D}_{d}=D_{d}^{*}$ ) and $H(Q, s)$ satisfies conditions (7) and (8), $d \pi_{R} / d s_{r}=0$. A similar argument holds for the manufacturer. Therefore, $\left\{\hat{s}_{r}\right.$, $\left.\hat{s}_{d}\right\}=\left\{s_{r}^{*}, s_{d}^{*}\right\}$ represents a Nash equilibrium and coordination will be achieved.

For the wholesale price scheme described in part (b), $H_{s}^{\prime}\left(D_{r}, s_{r}\right)=0$. This precludes coordination since the conditions laid out in part (a) obviously cannot be met.

\section{Derivation of Expressions in Table 4}

The profit functions for system $\mathrm{RD}$ are

$$
\begin{gathered}
\pi_{R}=\beta p \cdot(1-\chi)\left(b_{r} s_{r}+b_{d} s_{d}\right)-\eta_{r} s_{r}^{2} / 2 \\
\pi_{M}=\left(p-c_{d}\right)\left(b_{r} s_{r}+b_{d} s_{d}\right)- \\
\eta_{d} s_{d}^{2} / 2-\beta p \\
\cdot(1-\chi)\left(b_{r} s_{r}+b_{d} s_{d}\right)=\left(p(1-\beta(1-\chi))-c_{d}\right) \\
\times\left(b_{r} s_{r}+b_{d} s_{d}\right)-\eta_{d} s_{d}^{2} / 2 .
\end{gathered}
$$

The term $\beta p \cdot(1-\chi)\left(b_{r} s_{r}+b_{d} s_{d}\right)$ represents the total payment to the reseller in commissions.

It is straightforward to show that, for a given $\beta$, the reseller's profit, as stated in (14), is maximized at the sales effort level $\hat{s}_{r}(\beta)=\beta p b_{r}(1-\chi) / \eta_{r}$. Increasing $\chi$ will reduce the effort provided for a given $\beta$. Hence, the lower the underlying tendency of customers to visit the reseller (and therefore to generate a commission), the less effort the reseller will provide. The manufacturer will then need to increase $\beta$ to achieve a desired effort.

Substituting $\hat{s}_{r}(\beta)$ into (15) delivers the following expression for the manufacturer's profit:

$$
\begin{aligned}
\hat{\pi}_{M}\left(\beta, s_{d}\right)=\left(p(1-\beta(1-\chi))-c_{d}\right)\left(\beta p\left(b_{r}\right)^{2}(1-\chi) / \eta_{r}\right. & \\
& \left.+b_{d} s_{d}\right)-\eta_{d} s_{d}^{2} / 2 .
\end{aligned}
$$

The Hessian of this is

$$
\left|\begin{array}{cc}
-2\left(p b_{r}(1-\chi)\right)^{2} / \eta_{r} & -p b_{d}(1-\chi) \\
-p b_{d}(1-\chi) & -\eta_{d}
\end{array}\right|
$$

so $\hat{\pi}_{M}\left(\beta, s_{d}\right)$ is strictly concave as long as $2 \eta_{d}\left(b_{r}\right)^{2}-\eta_{r}\left(b_{d}\right)^{2}$ $>0$, which is true by (1). Hence, the manufacturer's optimal decisions can be obtained by solving the first-order conditions to obtain $\beta^{*}=Y\left(p-c_{d}\right) /[p(1-\chi)]$ and $s_{d}^{*}=\left(b_{d} /\right.$ $\left.\left(2 \eta_{d}\right)\right)(Y+Z)\left(p-c_{d}\right)$, so that $s_{r}^{*}=\left(b_{r} / \eta_{r}\right) Y\left(p-c_{d}\right)$. Total demand in the direct channel is then $\left(b_{r} s_{r}^{*}+b_{d} s_{d}^{*}\right)=\left[\left(b_{r}\right)^{2} /\right.$ $\left.\left(2 \eta_{r}\right)\right](Y+Z)\left(p-c_{d}\right)$, a fraction $(1-\chi)$ of which was referred by the reseller. The equilibrium profits follow directly from these expressions.

The profit functions for system RR are

$$
\begin{aligned}
& \pi_{R}=(p-w)\left(b_{r} s_{r}+b_{d} s_{d}\right)-\eta_{r} s_{r}^{2} / 2 \\
& \pi_{M}=\left(w-c_{r}\right)\left(b_{r} s_{r}+b_{d} s_{d}\right)-\eta_{d} s_{d}^{2} / 2
\end{aligned}
$$


We omit the derivation of the resulting equilibrium since it is similar to the approach used to compute the equilibria for B and RD.

Proof of Proposition 4. The rank-ordering of the profits for each party across the three schemes follow directly from the expressions in Tables 2 and 4.

\section{References}

Ahn, H., I. Duenyas, R. Q. Zhang. 2002. Price competition between retailers and manufacturer-owned stores. Working Paper, University of California at Berkeley.

Artle, R., S. Berglund. 1959. A note on manufacturers' choice of distribution channels. Management Science 5(2) 460-471.

Axsater, S. 1993. Continuous review policies for multi-level inventory systems with stochastic demand. In S. C. Graves, A. H. G. Rinnooy Kan, P. H. Zipkin (eds.). Handbooks in operations research and management science, vol. 4 (Logistics of production and inventory). Elsevier Science Publishing Company B.V., Amsterdam, The Netherlands 175-197.

Balderston, F. E. 1958. Communication networks in intermediate markets. Management Science 4(2) 154-171.

Baligh, H. H., L. E. Richartz. 1964. An analysis of vertical market structures. Management Science 10(4) 667-689.

Bannon, L. 2000. Selling Barbie online may pit Mattel vs. stores. The Wall Street Journal, November 17 B1.

Bell, D. R., Y. Wang, V. Padmanabhan. 2002. An explanation for partial forward integration: Why manufacturers become marketers. Working Paper, The Wharton School, University of Pennsylvania.

Bolton, P., G. Bonanno. 1987. Vertical restraints in a model of vertical differentiation. Unpublished manuscript, Harvard University, Cambridge, Massachusetts.

Bowman Jr., W. S. 1955. Prerequisites and effects of resale price maintenance. University of Chicago Law Review 22 825-873.

Boyaci, T. 2001. Manufacturer-retailer competition and coordination in a dual distribution system. Working paper, McGill University.

Brooker, K. 1999. E-rivals seem to have Home Depot awfully nervous. Fortune 140(4) 28-29.

Bucklin, C. B., P. A. Thomas-Graham, E. A. Webster. 1997. Channel conflict: When is it dangerous? The McKinsey Quarterly June 22 36.

Chen, F., A. Federgruen, Y. Zheng. 2001. Coordination mechanisms for a distribution system with one supplier and multiple retailers. Management Science 47(5) 693-708.

Chiang, W. K., D. Chhajed, J. D. Hess. 2002. Direct marketing, indirect profits: A strategic analysis of dual-channel supply chain design. Working paper, University of Maryland Baltimore County, Baltimore.

Choi, S. C. 1996. Price competition in a duopoly common retailer channel. Journal of Retailing 72(2) 117-134.

Cohen, M. A., N. Agrawal, V. Agrawal, A. Raman. 1995. Analysis of distribution strategies in the industrial paper and plastics industry. Operations Research 43(1) 6-18.

Cohen, M. A., P. Kleindorfer, H. L. Lee. 1990. OPTIMIZER: A multi-echelon inventory system for service logistics management. Interfaces 20(1) 65-82.

Cohen, M. A., S. Whang. 1997. Competing in product and service: a product life-cycle model. Management Science 43(4) 535-545.

Cohen, M. A., Y. Zheng, Y. Wang. 1999. Identifying opportunities for improving Teradyne's service-parts logistics system. Interfaces 29(4) 1-18.

Collinger, T. 1998. Lines separating sales channels blur: Manufacturers, direct sellers, retailers invade each other's turf. Advertising Age March 3034
Corstjens, M., P. Doyle. 1979. Channel optimization in complex marketing systems. Management Science 25(10) 1014-1025.

Desiraju, R., S. Moorthy. 1997. Managing a distribution channel under asymmetric information with performance requirements. Management Science 43(12) 1628-1644.

Dixit, A. K. 1983. Vertical integration in a monopolistically competitive industry. International Journal of Industrial Organization 1(1) 63-78

Federgruen, A. 1993. Centralized planning models for multi-echelon inventory systems under uncertainty. In S. C. Graves, A. H. G. Rinnooy Kan, P. H. Zipkin (eds.). Handbooks in operations research and management science, vol. 4 (Logistics of production and inventory). Elsevier Science Publishing Company B.V., Amsterdam, The Netherlands 133-173.

Frazier, G. L. 1999. Organizing and managing channels of distribution. Journal of the Academy of Marketing Science 27(2) 226-241.

Garner, R. 1999. Mad as hell. Sales \& Marketing Management June 1 54.

Ghosh, S. 1998. Making business sense of the Internet. Harvard Business Review 76(2) 126-135.

Girishankar, S. 1998. IBM to sell product line over Web. CMP TechWeb February 19.

Goldman, A. 1999. Battle for Web customers pits retailer against manufacturer; Internet: now that product makers can open virtual shops accessible to every online customer, traditional merchants are beginning to show their displeasure. Los Angeles Times August 8 C-1.

Hamel, G., J. Sampler. 1998. The e-corporation. Fortune 138(11) December 7, 88-100.

Hendershott, T., J. Zhang. 2001. A model of direct and intermediated sales. Working paper, University of California at Berkeley and University of Rochester.

Ingene, C. A., M. E. Parry. 1995. Channel coordination when retailers compete. Marketing Science 14(4) 360-377.

Ingene, C. A., M. E. Parry. 1998. Manufacturer-optimal wholesale pricing when retailers compete. Marketing Letters 9(1) 65-77.

Jaikumar, R., V. K. Rangan. 1990. Price discounting in multi-echelon distribution systems. Engineering Costs and Production Economics 19(1-3) 341-349.

Janah, M. 1999. Tech firms slow to use direct web sales. San Jose Mercury News February 24 C1.

Jeuland, A. P., S. M. Shugan. 1983. Managing channel profits. Marketing Science 2(3) 239-272.

Katz, M. L. 1989. Vertical contractual relations. In R. Schmalensee, R. D. Willig (eds.). Handbook of industrial organization, vol. 1. Elsevier Science Publishers, The Netherlands 655-721.

Kravetz, S. 1999. Mattel's new retail plan aims to boost direct sales. The Wall Street Journal Europe February 18.

Lee, H. L., V. Padmanabhan, S. Whang. 1997. Information distortion in a supply chain: the bullwhip effect. Management Science $\mathbf{4 3}(4)$ 546-558.

Machlis, S. 1998a. Channel conflicts stall web sales. Computerworld February 162.

Machlis, S. 1998b. Going online, Lauder remembers retailers. Computerworld July 679.

Machlis, S. 1998c. Beauty product sites facing channel clash. Computerworld November 924.

Margretta, J. 1998. The power of virtual integration: an interview with Dell Computer's Michael Dell. Harvard Business Review 76(2) 73-84.

Marvel, H. P., S. McCafferty. 1984. Resale price maintenance and quality certification. Rand Journal of Economics 15(3) 346-359.

Mathewson, G. F., R. A. Winter. 1984. An economic theory of vertical restraints. Rand Journal of Economics 15(1) 27-38.

McAfee, R., M. Schwarz. 1994. Opportunism in multilateral vertical 
contracting: Nondiscrimination, exclusivity, and uniformity. The American Economic Review 84(1) 210-230.

McGuire, T. W., R. Staelin. 1983. An industry equilibrium analysis of downstream vertical integration. Marketing Science 2(2) 161-191.

McGuire, T. W., R. Staelin. 1986. Channel efficiency, incentive compatibility, transfer pricing, and market structure: An equilibrium analysis of channel relationships. Research in marketing, 8 . JAI Press Inc. 181-223.

McIntyre, S. J. 1997. How to reap profits and avoid pitfalls when a catalog is only part of your business, Pt. 2. Direct marketing June 132.

McWilliams, G. 1998. Mimicking Dell, Compaq to sell its PCs directly. The Wall Street Journal November 11 B1.

Moorthy, K. S. 1987. Managing channel profits: Comment. Marketing Science 6(4) 375-379.

Moorthy, K. S. 1993. Competitive marketing strategies: Game-theoretic models. In J. Eliashberg, G. L. Lilien (eds.). Handbooks in operations research and management science, vol. 5. Elsevier Science Publishers, The Netherlands 143-190.

Muckstadt, J. A., R. O. Roundy. 1993. Analysis of multistage production systems. In S. C. Graves, A. H. G. Rinnooy Kan, P. H. Zipkin (eds.). Handbooks in operations research and management science, vol. 4 (Logistics of production and inventory). Elsevier Science Publishing Company B.V., Amsterdam, The Netherlands 59-131.

Naert, P. A. 1971. Optimizing consumer advertising, intermediary advertising and markup in a vertical market structure. Management Science 18(4) 90-101.

Nasireti, R. 1998. IBM plans to sell some gear directly to fight its rivals. The Wall Street Journal June 5.

O'Brien, D. P., G. Shaffer. 1992. Vertical control with bilateral contracts. RAND Journal of Economics 23(3) 299-308.

Oi, W. 1971. A Disneyland dilemma: Two-part tariffs for a Mickey Mouse monopoly. Quarterly Journal of Economics 85 77-90.

Peleg, B., H. L. Lee. 2002. Secondary markets for product diversion with potential manufacturer's intervention. Working paper, Department of Management Science and Engineering, Stanford University.

Perry, M. K., R. H. Porter. 1990. Can resale price maintenance and franchise fees correct sub-optimal levels of retail service. International Journal of Industrial Organization 8(1) 115-141.

Rangan, V. K. 1987. The channel decision: A model and an application. Marketing Science 6(2) 156-174.

Rangan, V. K., R. Jaikumar. 1991. Integrating distribution strategy and tactics: A model and an application. Management Science 37(11) 1377-1389.
Reinhardt, G., M. Levesque. 2001. Virtual versus bricks-and-mortar retailing. Working paper, Department of Management, Depaul University, Chicago, Illinois.

Rhee, B. 2001. A hybrid channel system in competition with net-only direct marketers. Working paper, HKUST.

Rhee, B., S. Y. Park. 2000. Online stores as a new direct channel and emerging hybrid channel system. Working paper, HKUST.

Schmalensee, R. 1981. Monopolistic two-part pricing arrangements. Bell Journal of Economics 11(Autumn) 445-466.

Schmid, J. 1999. Reaching into retail: Can the catalog and retail marketing channels coexist? Catalog Age January 59-62.

Schonfeld, E. 1998. The customized, digitized, have-it-your-way economy. Fortune 138(6) 114-124.

Silcock, T. H. 1938. Some problems of price maintenance. Economic Journal 48 42-51.

Spengler, J. J. 1950. Vertical integration and antitrust policy. Journal of Political Economy 58(4) 347-352.

Stern, L. W., A. I. El-Ansary, A. T. Coughlan. 1996. Marketing channels, 5th edition. Prentice Hall, Upper Saddle River, New Jersey.

Tedeschi, B. 1999. What a tangled Web they weave: The rush to e-commerce pits brick-and-mortar retailers against unlikely competition-their own suppliers. National Post March 3 C16.

Telser, L. G. 1960. Why should manufacturers want fair trade? Journal of Law and Economics 3 86-105.

Tirole, J. 1988. The theory of industrial organization. The MIT Press, Cambridge, Massachusetts.

Trivedi, M. 1998. Distribution channels: An extension of exclusive retailership. Management Science 44(7) 896-909.

Tsay, A. A., N. Agrawal. 2000. Channel dynamics under price and service competition. Manufacturing \& Service Operations Management 2(4) 372-391.

Tsay, A. A., S. Nahmias, N. Agrawal. 1999. Modeling supply chain contracts: a review. In S. Tayur, R. Ganeshan, M. Magazine (eds.). Quantitative models for supply chain management. Kluwer Academic Publishers, Norwell, Massachusetts 299-336.

Tsay, A. A., N. Agrawal. 2002. Modeling conflict and coordination in multi-channel distribution systems: A review, forthcoming. In D. Simchi-Levi, D. Wu, M. Shen (eds.). Supply chain analysis in the eBusiness era. International Series in Operations Research and Management Science, Kluwer Academic Publishers.

White, L. J. 1981. Vertical restraints in antitrust law: A coherent model. The Antitrust Bulletin 26(2) 327-345.

Yamey, B. S. 1954. The economics of resale price maintenance. Sir Isaac Pitman, London. 